INTRODUCTION TO THE THEORY

OF THE RAMAN EFFECT 


\title{
INTRODUCTION
}

\section{TO THE THEORY OF THE} RAMAN EFFECT

by

\author{
J. A. KONINGSTEIN
}

Carleton University, Ottawa, Canada

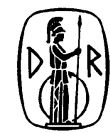

D. REIDEL PUBLISHING COMPANY

DORDRECHT-HOLLAND 
Library of Congress Catalog Card Number 72-77876

ISBN-13: 978-90-277-0276-0

e-ISBN-13: 978-94-010-2901-8

DOI: $10.1007 / 978-94-010-2901-8$

All Rights Reserved

Copyright $\odot 1972$ by D. Reidel Publishing Company, Dordrecht, Holland Softcover reprint of the hardcover lst edition 1972

No part of this book may be reproduced in any form, by print, photoprint, microfilm, or any other means, without written permission from the publisher 
to $M . G$. 


\section{INTRODUCTION}

This book is written particularly for chemists. Being one myself, I have on several occasions tried to find a book where the theory of molecular Raman spectroscopy is treated, and not being able to find one which satisfactorily answered the questions I wanted to see answered, I decided to try to write a book on it myself.

Back in the middle fifties I was shown a Raman spectrum for the first time: some faint lines on a photographic plate. In the fall of 1971, during a visit to Moscow, I vividly remembered that spectrum when the son of Mandel'shtam showed me the first spectrum taken in Russia by his father and Landsberg in 1928. The spectrum of quartz photographed during January and February of that year showed the presence of some faint new lines and in later exposures these lines became stronger and stronger. Dr Mandel'shtam told me that his father had asked Landsberg to carry out more experiments to make sure that these lines, which they could not observe in the spectrum of the mercury lamp, were genuine. Originally they were looking for what we now call a Brillouin spectrum of quartz and the rather large shifts observed were not expected.

Sir C. V. Raman, who died when this book was being written, became interested in light scattering of liquids during a trip to Europe in 1921. Travelling by steamer he became fascinated by the colour of the Mediterranean Sea and back in India he commenced light scattering experiments with liquids. In the course of these experiments, which he carried out together with Krishnan and Venkatesvaran, frequency shifted lines were observed in the spectrum of liquid benzene on 28 February, 1928. The discovery was published in Nature (31 March and 21 April, 1928) while the Mandel'shtam and Landsberg article appeared in Die Naturwissenschaften. Their publication concluded with the following remark: "At this moment (6 May, 1928), it is not possible for us to judge if, and to what extent, there exists a relation between the phenomenon observed by us and that for the first time shortly discussed by Raman, because of the brevity of his description". They thus acknowledged Raman's work.

In actual fact, the Austrian physicist Smekal had already in 1923 predicted the possibility of the occurrence of frequency shifted lines, but Raman was not aware of his work. Also in 1928, Cabannes and Rocard in France tried to detect frequency shifted lines in the spectrum of gases, but they gave up their attempts.

The basis of this book can be found in Placzek's paper in Marx's Handbuch der Radiologie. There he explained the details of the molecular Raman effect, and using his results it is easy to find the formulas for the hyper, stimulated (and inverse), and electronic Raman effect. 
However, a period of more than thirty years elapsed before these processes became more familiar to us. While early as 1930 Rasetti had already found an electronic Raman effect and Stoicheff had tried to observe induced absorption before the advent of the laser, the first stimulated Raman spectrum was excited and observed by Woodbury and $\mathrm{Ng}$ in 1962. Stoicheff and Jones observed the inverse Raman spectrum in 1963, and the hyper Raman effect was found in 1965 by Terhune, Maker, and Savage in 1965. Laser excited electronic Raman effects were observed in 1966. The frustrations and disappointments encountered by who knows how many scientists trying to get spectra of solids during the pre-laser period were legio. Many of the difficulties have now been removed - one has only to look at the results obtained by Porto and coworkers in the late sixties on single crystals.

This book provides background information on the theory of molecular Raman spectroscopy. I have tried for instance to introduce the irreducible tensor components and their relevance to electronic and rotational Raman spectroscopy. In order to keep the book to a reasonable size I have assumed of the reader some knowledge of group theory and quantum mechanics. At the same time, the reader should not expect to find Raman spectra of compounds, frequencies of fundamental vibrations, etc., but he may be able to handle the Raman activity of the lines of the various Raman processes, even if it comes to employing double groups.

I am greatly indebted to O. Sonnich Mortensen for his work on the irreducible tensors, and I have also benefited from discussions with H. J. Bernstein and W. F. Murphy and G. Herzberg who kindly lent me the book containing Placzek's paper.

Finally I wish to thank Mrs A. Ratz for typing and correcting the manuscript. I of course take full responsibility for the contents of the book and for the fact that the language is not quite perfect. Its preparation took up much of my time, which I otherwise would have spent with my family.

Ottawa and Paris, 1971 


\section{TABLE OF CONTENTS}

I-1. Electromagnetic Radiation of an Oscillating Dipole

I-2. Higher Order Moments: Quadrupoles and Magnetic Dipoles

I-3. Spectroscopic Transitions

I-4. Classical Considerations of the Radiation Field and Quantum Mechanical Calculation of the Induced Dipole Moment, the Correspondence Principle

I-5. Formulation of the Scattering Tensor 23

I-6. Symmetry of the Scattering Tensors 29

CHAPTER II. PROPERTIES OF TENSORS

II-1. Vectors and Dyadics

II-2. Scattering Tensors and Radiation from Classical Oscillators 39

II-3. Rotation of Tensors $\quad 44$

II-4. Specific Rotation of Symmetric and Antisymmetric Tensors 49

$\begin{array}{lc}\text { CHAPTER III. SOME ASPECTS OF GROUP THEORY } & 56\end{array}$

III-1. Symmetry Elements 56

III-2. Definition Properties of Point, Space and Factor Groups 59

III-3. Representations of Groups $\quad 62$

III-4. Transformation Properties of the Scattering Tensor 66

III-5. Irreducible Tensors and Their Transformation Properties 70

III-6. The Scattering Operator 76

$\begin{array}{ll}\text { CHAPTER IV. THE NORMAL RAMAN EFFECT } & 79\end{array}$

IV-1. Theory of the Electronic Raman Effect $\quad 80$

IV-2. Electronic Levels and Selection Rules 84

IV-3. Normal Modes, Normal Coordinates and Vibrational Wave Functions 91

IV-4. Theory of the Vibrational Raman Effect 100 
IV-5. The Case of Degenerate Electronic States $\quad 110$

IV-6. Rotational Levels and Wave Functions $\quad 112$

IV-7. The Rotational Raman Effect $\quad 115$

IV-8. Depolarization Ratios 125

$\begin{array}{ll}\text { CHAPTER V. OTHER SCATTERING PROCESSES } & 134\end{array}$

V-1. The Hyper Raman Effect 135

$\begin{array}{ll}\text { V-2. The Stimulated Raman Effect } & 137\end{array}$

V-3. Induced Absorption: The Inverse Raman Effect 142

V-4. The Resonance Raman Effect 145

APPENDIX I. PROPERTIES OF REPRESENTATIONS OF SOME IMPORTANT POINT GROUPS 151

$\begin{array}{ll}\text { INDEX } & 164\end{array}$ 